\title{
Anticancer activity of caffeic acid n-butyl ester against A431 skin carcinoma cell line occurs via induction of apoptosis and inhibition of the mTOR/PI3K/AKT signaling pathway
}

\author{
NING ZENG, TANG HONGBO, YI XU, MIN WU and YIPING WU \\ Department of Plastics and Aesthetic Surgery, Tongji Hospital, Tongji Medical College, \\ Huazhong University of Science and Technology, Wuhan, Hubei 430030, P.R. China
}

Received July 15, 2017; Accepted November 13, 2017

DOI: $10.3892 / \mathrm{mmr} .2018 .8599$

\begin{abstract}
Skin cancer is one of the primary causes of mortality worldwide. With an increasing frequency of skin cancers, there is an urgent requirement for the development of numerous treatment options. The present study investigated the anticancer activity of caffeic acid n-butyl ester (CAE) against the A431 skin cancer cell line. Antiproliferative effects were investigated using an MMT assay. Apoptosis was examined by DAPI and Annexin V/fluorescein isothiocyanate and propidium iodide staining. Reactive oxygen species (ROS), mitochondrial membrane potential (MMP) and cell cycle analyses were performed via flow cytometry Protein expression was determined by western blotting. The findings of the present study demonstrated that among a variety of cancer cell lines, CAE exhibited significant anticancer activity against the A431 skin cancer cell line with a half-maximal inhibitory concentration of $20 \mu \mathrm{M}$. CAE was associated with apoptosis and cell cycle arrest of A431 cells, and induced ROS-mediated alterations in MMP. In addition, CAE considerably suppressed the expression of some of the important proteins of the phosphoinositide 3-kinase (PI3K)/protein kinase B (AKT)/mechanistic target of rapamycin (mTOR) cascade. The results of the present study indicated that CAE exerted anticancer effects on the A431 skin carcinoma cell line via the induction of apoptosis and suppression of the PI3K/AKT/mTOR signaling pathway. Therefore, CAE may be beneficial for the development of chemotherapy for skin cancers.
\end{abstract}

Correspondence to: Dr Yiping Wu, Department of Plastics and Aesthetic Surgery, Tongji Hospital, Tongji Medical College, Huazhong University of Science and Technology, 1095 Jie Fang Avenue, Wuhan, Hubei 430030, P.R. China

E-mail: yuipingwu@hotmail.com

Key words: skin carcinoma, mechanistic target of rapamycin, reactive oxygen species, apoptosis, caffeic acid n-butyl ester

\section{Introduction}

Skin cancer is one among the primary causes of mortality worldwide (1). It has been previously estimated that $\sim 1$ in every 5 Americans will develop skin cancer (2). The increasing prevalence of skin cancer requires novel treatment options for the management of skin cancer. Preliminary responses to chemotherapy and/or surgical interventions are available; however, the persistence of tumor relapse has been previously observed (3). In addition, the side effects associated with synthetic drugs severely affect the quality of life of patients. Drugs from natural sources have gained considerable attention. Flavonoids form one of the largest groups of plant-derived secondary metabolites that have evolved across the plant kingdom billions of years ago. Flavonoids are an important part of almost all edible plants, which include, but are not limited to, fruits and vegetables. Therefore, flavonoids are consumed in significant amounts as part of a healthy diet. It has been previously reported that humans consume $\sim 30 \mathrm{mg}$ flavonoids daily (4). Furthermore, flavonoids are present in a number of medicinally important plants; herbal preparations have been extensively used in traditional systems of medicine, particularly in China (5). With advancements in medical research, flavonoids are being investigated for variation in bioactivities. These compounds have been reported to exhibit various bioactivities, including anti-inflammatory, estrogenic, enzyme inhibition, antimicrobial, anti-allergy, antioxidant and antitumor $(4,6)$. There is considerable epidemiological evidence on the anticancer effects of flavonoids. A number of epidemiological studies have indicated that high flavonoid intake may be correlated with a reduced risk of cancer $(7,8)$. As these compounds have a fairly consistent structure, flavonoids impede the activity of a wide range of eukaryotic enzymes; therefore, they exhibit variation in activities. The structural parts of flavonoid molecules have been considered critical for their bioactivities $(7,8)$. Additionally, flavonoids are ubiquitously present in edible plants and beverages and are believed to have minimal toxicity. The present study evaluated the anticancer activity of a natural flavonoid, caffeic acid n-butyl ester (CAE) in various cell lines. CAE exhibited the highest activity against the A431 skin carcinoma cell line. CAE induced A431 cell apoptosis, which may have 
been mediated by reactive oxygen species (ROS) accretion and reductions in mitochondrial membrane potential (MMP). Furthermore, CAE inhibited the expression of some of the key proteins of phosphoinositide 3-kinase (PI3K)/protein kinase B $(\mathrm{AKT}) / \mathrm{mechanistic}$ target of rapamycin (mTOR) signaling pathway, which has been considered an important target for treatment of different types of cancers. Therefore, CAE may be beneficial in the treatment and management of skin carcinoma; however, further investigation is required.

\section{Materials and methods}

Chemicals and reagents. The following chemicals were used in the present study. CAE, RNase A, Triton X-100 and dimethyl sulfoxide (DMSO), were purchased from Sigma-Aldrich (Merck KGaA, Darmstadt, Germany). Primary and secondary antibodies were obtained from Santa Cruz Biotechnology, Inc. (Dallas, TX, USA). The fluorescent probes DCFH-DA, DiOC6, DAPI, propidium iodide (PI), fetal bovine serum (FBS), RPMI-1640 medium, L-glutamine and antibiotics were obtained from Invitrogen (Thermo Fisher Scientific, Inc., Waltham, MA, USA).

Cell line and culture conditions. Human lung cancer cell line (A549), pancreas (MIA PaCa-2), prostate (PC-3), breast (MCF-7), gastric (SNU-5), colon (HTB-39), normal human fibroblast FR2 and skin cancer (A431) cell lines were obtained from the Cancer Research Institute of Beijing (Beijing, China) and were cultured continuously in RPMI-1640 supplemented with $10 \%$ FBS containing antibiotics, $100 \mu \mathrm{g} / \mathrm{ml}$ streptomycin and $100 \mathrm{U} / \mathrm{ml}$ penicillin $\mathrm{G}$ and maintained at $37^{\circ} \mathrm{C}$ and $5 \% \mathrm{CO}_{2}$.

Proliferation assay. The anti-proliferative effects of CAE were investigated in the 8 aforementioned cell lines using an MTT assay. All cells were cultured at $37^{\circ} \mathrm{C}$ at a density of $1 \times 10^{6}$ cells/well in 96-well plates for $12 \mathrm{~h}$. The cells were then subsequently treated with $0-200 \mu \mathrm{M}$ CAE for $24 \mathrm{~h}$. Subsequently, $20 \mu \mathrm{l}$ MTT solution was added to each well. Prior to the addition of $500 \mu \mathrm{l}$ DMSO, the medium was completely removed. The MTT formazan crystals were dissolved by adding $500 \mu \mathrm{l}$ DMSO. The absorbance was detected using an ELISA plate reader (optical density at $570 \mathrm{~nm}$ ). As CAE exhibited the lowest half-maximal inhibitory concentration $\left(\mathrm{IC}_{50}\right)$ against A431 cells, subsequent experiments were conducted within this cell line at concentrations of $0,10,20$ and $40 \mu \mathrm{M}$ CAE.

Colony formation assay. The effect of CAE on the colony formation potential of A431 cells was investigated when cells were collected at the exponential phase of growth and the cells were then counted using a hemocytometer. Cells were seeded at a density of 200 cells/well and maintained at $37^{\circ} \mathrm{C}$ for $48 \mathrm{~h}$ to permit cell adherence. Subsequently, 0, 10, 20 and $40 \mu \mathrm{M}$ CAE was administered. Following the treatment with CAE, cells were incubated at $37^{\circ} \mathrm{C}$ for 6 days. Following incubation, cells were washed with PBS and fixed with methanol at $-20^{\circ} \mathrm{C}$ for $4 \mathrm{~min}$ and then stained with crystal violet for $30 \mathrm{~min}$ at room temperature, then counted under a light microscope (magnification, x200).

Detection of apoptosis. A431 cells were seeded at the density of $1 \times 10^{6}$ cells/well in 6 -well plates and subsequently treated with $0,10,20$ and $40 \mu \mathrm{M}$ CAE for $24 \mathrm{~h}$, followed by DAPI staining at $25^{\circ} \mathrm{C}$ for $5 \mathrm{~min}$. Then, the cell samples were examined via fluorescence microscopy (magnification, x200).

Flow cytometry. A431 cells were plated at a density of $1 \times 10^{6}$ cells/well in 6-wellplates and treated with $0,10,20$ and $40 \mu \mathrm{M}$ CAE for $24 \mathrm{~h}$. Subsequently, the cells were collected and washed with PBS. The cells were then incubated with Annexin V/FITC and PI for $15 \mathrm{~min}$ at $25^{\circ} \mathrm{C}$, and apoptosis was estimated using flow cytometry and BD FACSuite software v1.0 (BD Biosciences, San Jose, CA, USA).

Cell cycle analysis. To investigate the dissemination of A431 cells in different phases of the cell cycle, $\sim 1 \times 10^{5}$ cells/well in 6 -well plates were maintained at $37^{\circ} \mathrm{C}$ overnight to allow cell adherence. Cells were then treated with $0,10,20$ and $40 \mu \mathrm{M}$ $\mathrm{CAE}$ and then the plates were incubated at $37^{\circ} \mathrm{C}$ for $24 \mathrm{~h}$. Subsequently, the cells were trypsinized and resuspended in ice-cold PBS, followed by treatment with ethanol (70\%) and allowed to fix overnight at $-20^{\circ} \mathrm{C}$. Following fixation with ethanol, cells were treated with ice-cold PBS twice and subjected to centrifugation $(800 \mathrm{x} \mathrm{g})$ for $10 \mathrm{~min}$ at $4^{\circ} \mathrm{C}$. Cells were then resuspended in $1 \mathrm{ml}$ PI/Triton-X 100 solution for 30 min in the dark. Finally, the dissemination of the cells at each phase were examined using 8,000 cells in a FACScan flow cytometer (BD Biosciences). The estimated percentage of cells in each phase of the cell cycle was quantified using WinMDI softwarev2.0 (Informer Technologies, Inc., Los Angeles, CA, USA).

Determination of ROS and MMP. A431 cells were seeded at a density of $2 \times 10^{5}$ cells/well in a 6-well plate and maintained for $24 \mathrm{~h}$ at $37^{\circ} \mathrm{C}$ and treated with $0,10,20$ and $40 \mu \mathrm{M}$ CAEfor $24 \mathrm{~h}$ at $37^{\circ} \mathrm{C}$ in $5 \% \mathrm{CO}_{2}$ and $95 \%$ air. Subsequently, cells from all samples were collected, washed twice with PBS and re-suspended in $500 \mu \mathrm{l}$ DCFH-DA $(10 \mu \mathrm{M})$ for ROS quantification or 3,3'-dihexyloxacarbocyanine iodide (1 $\mu \mathrm{mol} / 1$ ) for MMP analysis at $37^{\circ} \mathrm{C}$ in a dark room for $30 \mathrm{~min}$. The samples were then examined instantly using a flow cytometer (WinMDI software version 2.0 (Informer Technologies, Inc.).

Cell migration assay. Cell migration analysis was performed using the Boyden chamber assay with some modifications. Cells at the density of $5 \times 10^{4}$ cells/well were suspended in RPMI-1640 medium supplemented with 2\% FBS and placed in the upper chamber of $8-\mu \mathrm{m}$ pore size Transwell inserts. Subsequently, RPMI-1640 medium medium supplemented with $10 \%$ FBS was added to lower chamber, followed by an incubation for $24 \mathrm{~h}$ at $37^{\circ} \mathrm{C}$. On the upper surface of the membrane, non-migrated cells were removed and migrated cells on the lower surface of the membrane were fixed in $100 \%$ methanol and Giemsa stained at $20^{\circ} \mathrm{C}$ for $4 \mathrm{~h}$. Cell migration was estimated by counting the number of the migrated cells under a microscope (Olympus CH20i, Binocular version; Olympus Corporation, Tokyo, Japan, magnification, x200).

Western blotting analysis. Protein expression was determined by western blot analysis. The cells were lysed in lysis buffer [20 mM 4-(2-hydroxyethyl)-1-piperazineethanesulphonic 
Table I. $\mathrm{IC}_{50}$ of CAE against different cancer cell lines as determined by MTT assay.

\begin{tabular}{lc}
\hline Cell line & $\mathrm{IC}_{50}(\mu \mathrm{M})$ \\
\hline Gastric cancer SNU-5 & 30 \\
Lung cancer A-549 & 30 \\
Skin cancer carcinoma A431 & 20 \\
Prostate PC-3 & 30 \\
Breast MCF-7 & 40 \\
Pancreas MIA PaCa-2 & 40 \\
Colon HTB-39 & 30 \\
Human normal fibroblasts (FR2) & $>100$ \\
\hline
\end{tabular}

$\mathrm{IC}_{50}$, half-maximal inhibitory concentration.

acid, $350 \mathrm{mM} \mathrm{NaCl}, 20 \%$ glycerol, $1 \%$ Nonidet P 40, $1 \mathrm{mM}$ $\mathrm{MgCl}_{2}, 0.5 \mathrm{mM}$ EDTA, $0.1 \mathrm{mM}$ EGTA, $1 \mathrm{mM}$ DTT, $1 \mathrm{mM}$ PMSF, protease inhibitor cocktail and phosphatase inhibitor cocktail]. Briefly, proteins present in the cell extracts were resolved by $10 \%$ SDS-PAGE. This was followed by transfer on nitrocellulose membrane. The membrane was blocked with 5\% non-fat milk in PBS and then incubated with primary antibody primary antibody [AKT, sc-135829; phosphorylated (p)-AKT, sc-7985-R; PI3K, sc-136298; mTOR, sc-517464 and p-mTOR, sc-293133] for overnight at $4{ }^{\circ} \mathrm{C}$ (all 1:1,000), followed by incubation with horse radish peroxidase-conjugated (cat. no. 9003-99-0) and anti-rabbit secondary antibody (sc-2372) for $1 \mathrm{~h}$ at room temperature. All antibodies were purchased from purchased from Santa Cruz Biotechnology, Inc. The western blots were visualized using an enhanced chemiluminescence system (GE Healthcare, Chicago, IL, USA). The western blots were quantified by my Image Analysis software v1.0 (Thermo Fisher Scientific, Inc.).

Statistical analysis. The experiments were performed in triplicate and data are presented as the mean \pm standard deviation. Statistical analysis was performed sing a one-way analysis of variance followed by a Tukey's post-hoc test using GraphPad prism version 7 (GraphPad Software, Inc. La Jolla CA, USA). $\mathrm{P}<0.05$ was considered to indicate statistically significant difference.

\section{Results}

Anticancer effects of CAE on the A431 cell. In order to investigate the anticancer effects of CAE on various cancer cell lines, cells were treated with $\mathrm{CAE}$ at various concentrations and the $\mathrm{IC}_{50}$ was determined for each cell line (Table I). CAE exhibited significant anticancer effects on A431 cells with an observed $\mathrm{IC}_{50}$ of $20 \mu \mathrm{M}$. However, CAE exerted less cytotoxic effects on normal human fibroblasts (Table I). The effect of CAE on the cell viability demonstrated a dose-dependent manner (Fig. 1A). In addition, CAE treatment led to reduced A431 colony formation in a dose-dependent manner (Fig. 1B).

CAE induces the apoptosis of A431 cells. To examine whether the anticancer effects of CAE were due to the induction of
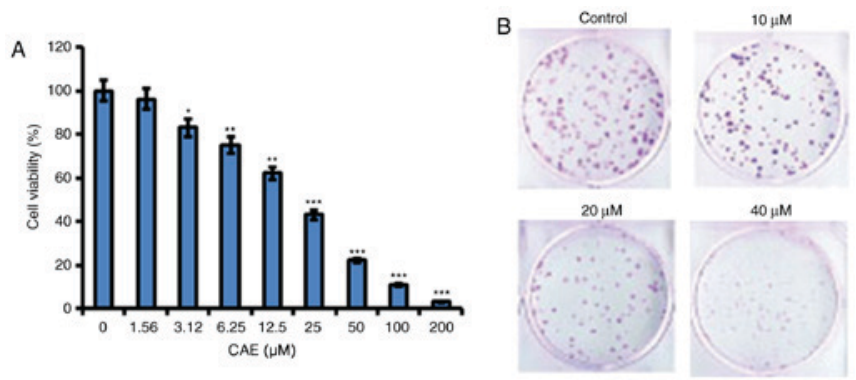

Figure 1. Effects of indicated concentrations of CAE on (A) cell viability and (B) colony formation. Data are presented as the mean \pm standard deviation of three independent experiments. ${ }^{*} \mathrm{P}<0.001,{ }^{* *} \mathrm{P}<0.001$ and ${ }^{* * * *} \mathrm{P}<0.0001$ vs control. CAE, caffeic acid n-butyl ester.

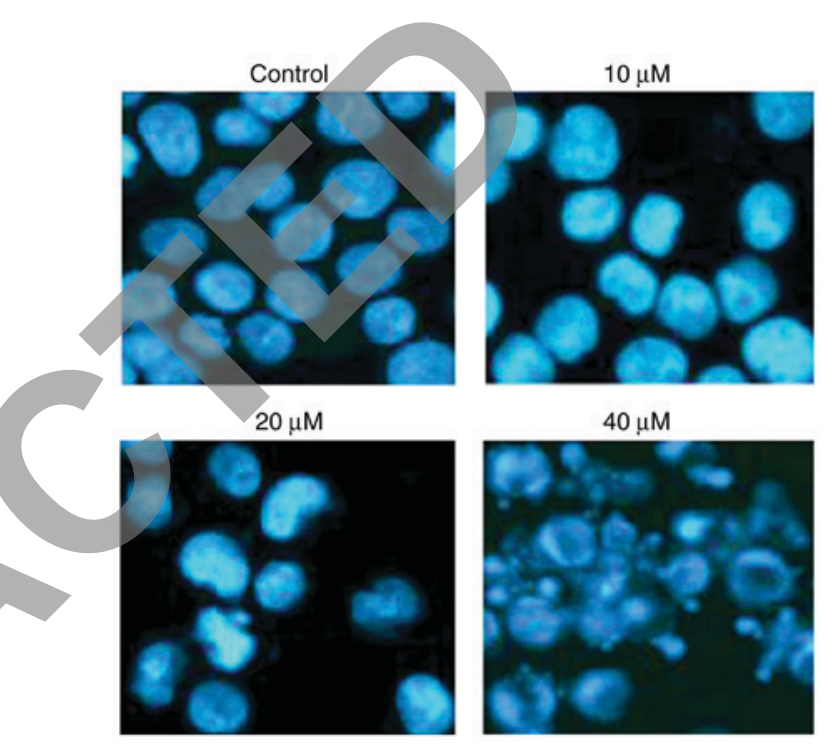

Figure 2. Induction of apoptosis by caffeic acid n-butyl ester at indicated concentrations as depicted by DAPI staining. All experiments were carried out in triplicate.

apoptosis, A431 cells were treated with CAE and apoptosis was determined by DAPI staining. The results of the present study demonstrated that CAE induced A431 cell apoptosis in a dose-dependent manner, as demonstrated by an increase in the number of cells with white-colored nuclei (Fig. 2). The number of apoptotic cells was determined using flow cytometry (Fig. 3). The percentage of apoptotic cells increased from $1.25 \%$ in the control to $46.37 \%$ in the $40 \mu \mathrm{M}$ CAE-treated group. In order to determine examine whether apoptosis occurred following the mitochondrial signalling pathway, the protein expression levels of B-cell lymphoma 2 (Bcl-2) and BCL2-associated $\mathrm{X}(\mathrm{Bax})$ were determined. The results of the present study revealed that the protein expression of Bax was upregulated in a dose-dependent manner, where as Bcl-2 expression levels were reduced with increased CAE concentration (Fig. 4).

CAE induces the activation of ROS and reduction of MMP. The pro-apoptotic potential of CAE observed via Annexin V/FITC staining indicated that CAE induced accretion of intracellular ROS. Therefore, the ROS levels in cells treated with various doses of CAE for $24 \mathrm{~h}$ were investigated. The findings of the present study revealed that the intracellular ROS levels of CAE-treated cells increased by $210 \%$ in the $40 \mu \mathrm{M}$ 

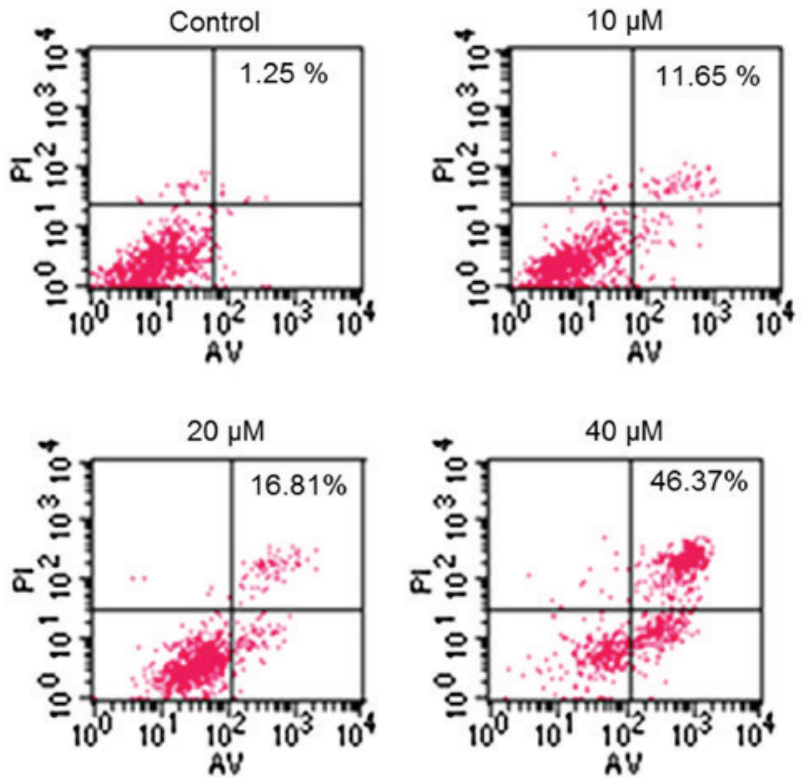

Figure 3. Estimation of apoptotic cell populations at indicated concentrations of caffeic acid n-butyl ester by Annexin V/propidium iodide staining followed by flow cytometry. Experiments were carried out in triplicate.
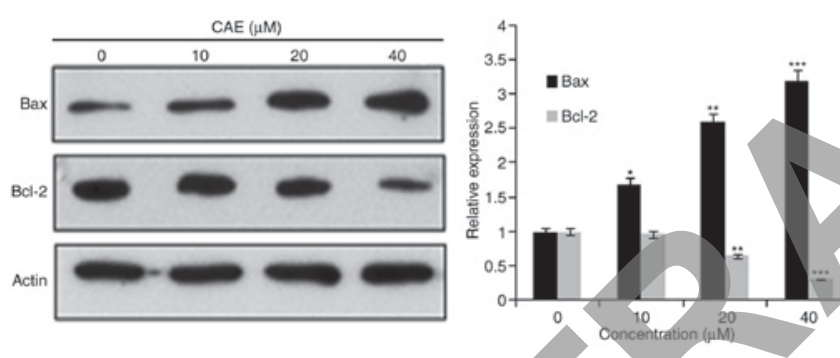

Figure 4. Effect of CAE on the protein expression of Bax and Bcl-2 was determined using western blot analysis. The experiments were carried out in triplicates. ${ }^{*} \mathrm{P}<0.001,{ }^{* *} \mathrm{P}<0.001$ and ${ }^{* *} \mathrm{P}<0.0001$ vs. control. Bcl-2, B-cell lymphoma 2; Bax, Bcl-2-associated X; CAE, caffeic acid n-butyl ester.

CAE-treated group (Fig. 5A). These observations indicated that CAE is an effective molecule that may stimulate the accumulation of ROS within A431 cells to induce apoptosis.

ROS generation is associated with mitochondrial dysfunction . ROS leads to an imbalance in the outer mitochondrial potential resulting in the release of apoptosis-inducing proteins (9). The effect of different CAE doses on MMP in A431 cells was investigated in the present study. CAE-treated A431 cells exhibited a marked reduction in MMP in a dose-dependent manner. The MMP was reduced $42 \%$ within the $40 \mu \mathrm{M}$ CAE-treated group (Fig. 5B).

CAE induces cell cycle arrest. To examine the impact of CAE on the cell cycle phase distribution of A431 cells, the cells were treated with $0,10,20$ and $40 \mu \mathrm{M}$ of CAE for $24 \mathrm{~h}$. The number of cells in the $\mathrm{G} 2$ phase increased in a dose-dependent manner leading to a cell cycle arrest (Fig. 6). CAE-treatment of $40 \mu \mathrm{M}$ was associated with a marked increase in G2 phase cells.

$C A E$ inhibits cell migration. The effects of CAE on cell migration of A431 cell migration were investigated (Fig. 7). The
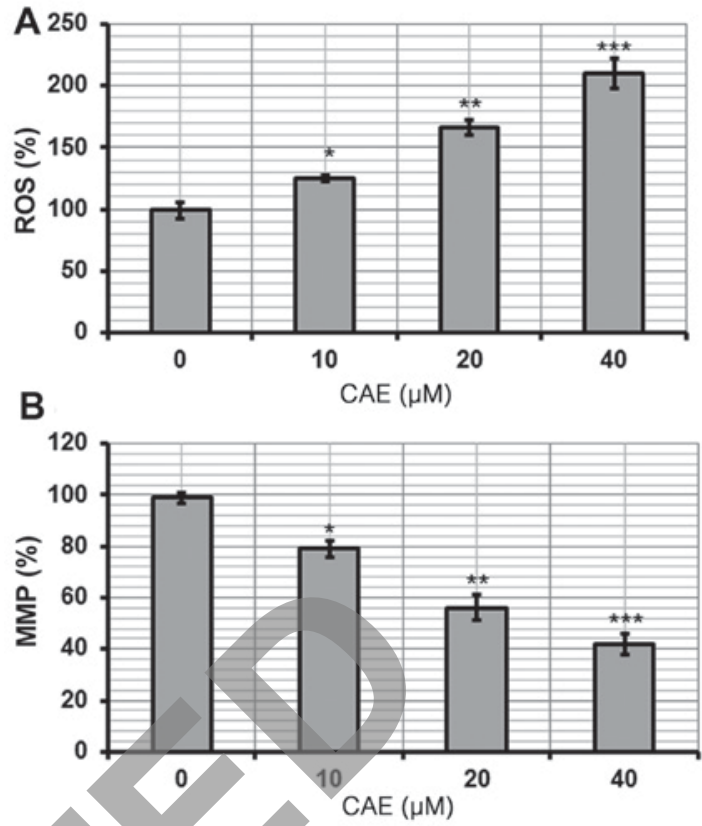

Figure 5. Effects of indicated concentration of CAE on (A) ROS generation and (B) MMP. Data are presented as the mean \pm standard deviation of three independent experiments. ${ }^{*} \mathrm{P}<0.001,{ }^{* *} \mathrm{P}<0.001$ and ${ }^{* * *} \mathrm{P}<0.0001$ vs. control. MMP, mitochondrial membrane potential; ROS, reactive oxygen species. CAE, caffeic acid n-butyl ester.
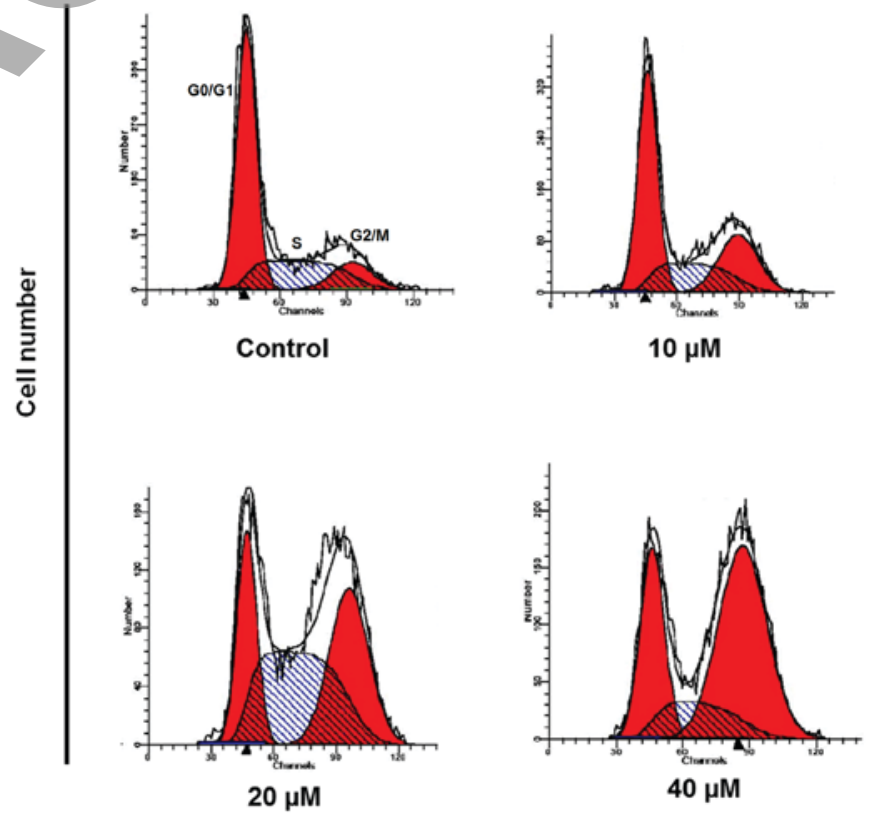

Figure 6. CAE triggers G2/M cell cycle arrest at indicated doses of CAE. Experiments were performed in triplicate. CAE, caffeic acid n-butyl ester.

results of cell migration assay following CAE treatment $(0,10$, 20 and $40 \mu \mathrm{M}$ ) for $24 \mathrm{~h}$ indicated that CAE reduced the motility and migration of the of A431 cells in a dose-dependent manner.

$C A E$ targets the $m T O R / P I 3 K / A K T$ signaling pathway. The mTOR/PI3K/AKT signalling cascade is considered to be one of the crucial pathways that maybe targeted for the treatment of cancer (9). In the present study, the effects of CAE on the expression levels of important pathway proteins were 

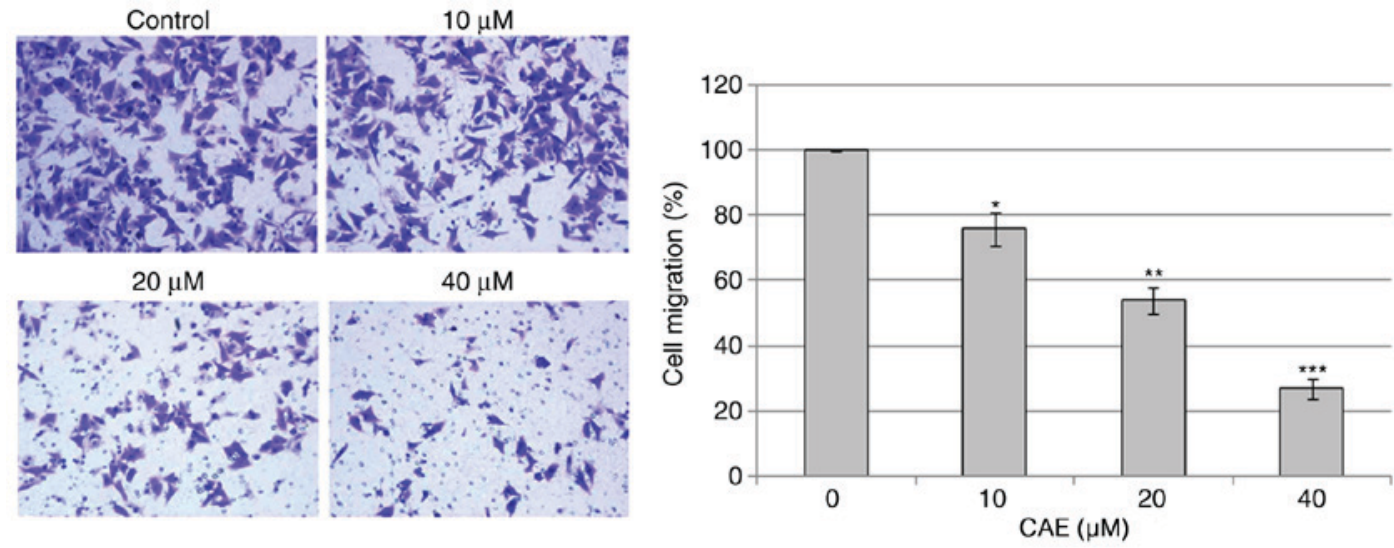

Figure 7. Effects of $\mathrm{CAE}$ on the migration of $\mathrm{A} 431$ cells at indicated concentrations. Experiments were performed in triplicate. ${ }^{*} \mathrm{P}<0.001,{ }^{* * *} \mathrm{P}<0.001$ and ${ }_{* * * *}^{*} \mathrm{P}<0.0001$ vs. control.

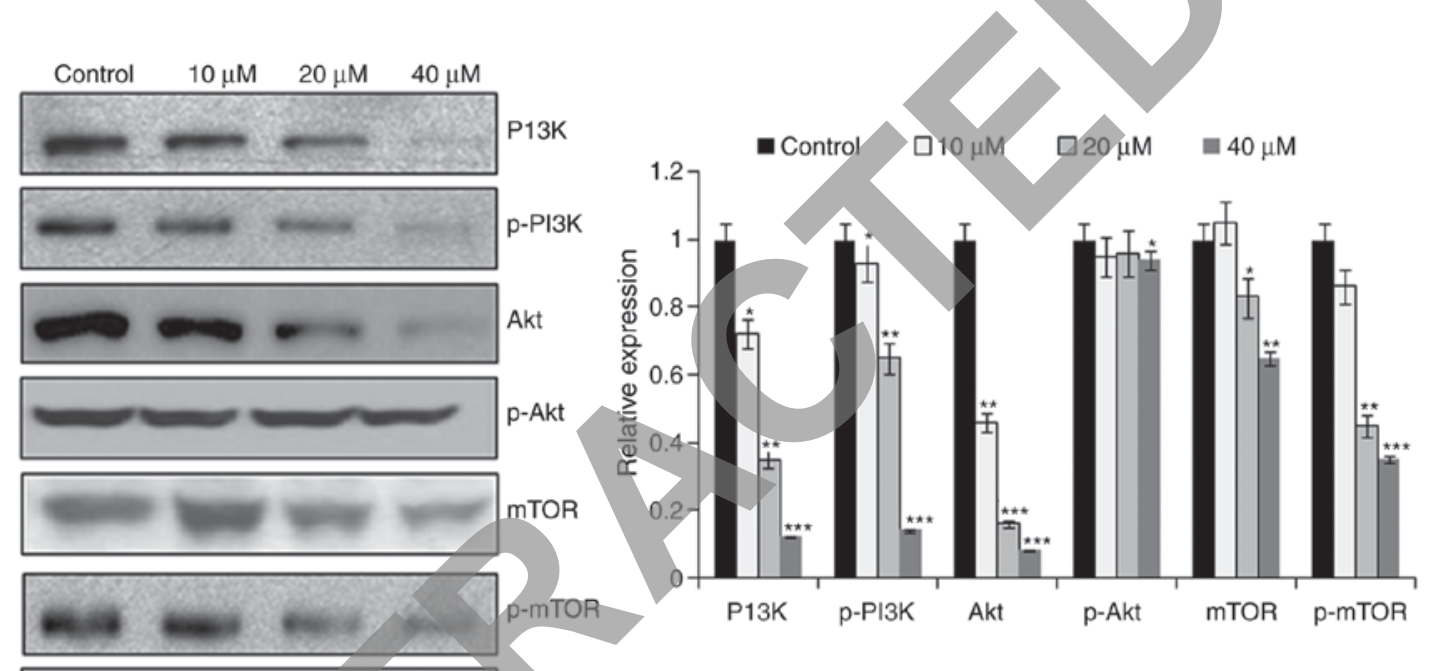

Figure 8. Western blot analysis demonstrated the effect of indicated concentrations of CAE on expression of mTOR/PI3K/AKT signaling pathway proteins. The experiments were performed in triplicates. ${ }^{*} \mathrm{P}<0.001,{ }^{* *} \mathrm{P}<0.001$ and ${ }^{* * * *} \mathrm{P}<0.0001$ vs. control. p, phosphorylated; AKT, protein kinase B; mTOR, mechanistic target of rapamycin; PI3K, phosphoinositide 3-kinase.

investigated. The results demonstrated that CAE-treated cells exhibited a dose-dependent downregulation of mTOR and p-mTOR compared with untreated cells (Fig. 8). In addition, $\mathrm{PI} 3 \mathrm{~K} / \mathrm{AKT}$ expression was also suppressed in response to CAE treatment. Therefore, CAE may have exhibited an anticancer effect via the mTOR/PI3K/AKT signalling cascade.

\section{Discussion}

Skin cancers are among the principal causes of mortality in humans, particularly in the Caucasian population (1). The increasing prevalence of skin malignancies demands the development of novel treatment strategies (1). Plants are considered to be important source of anticancer drugs; therefore, various natural compounds from plants have been used as anticancer drugs (10). CAE is an important flavonoid commonly found in several plant species and has been previously reported to exhibit a marked pharmacological potential (11). The anticancer effects of CAE on cervix adenocarcinoma, oropharyngeal carcinoma, breast cancer and melanoma have been previously reported (11). In the present study, the anticancer activity of CAE was investigated in various human cancer cell lines and normal human fibroblasts. The results indicated that CAE had a potent inhibitory effect on the growth and colony forming potential of A431 cells, as investigated via the proliferation and colony formation assays respectively. It has been demonstrated that various drugs inhibit growth by inducing apoptosis. For example, multiple chemotherapeutic agents, including cisplatin, taxol and 5-fluorouracil $(11,12)$ have been reported to alter specific apoptotic signalling pathways. In addition, the resistance of the cancer cells to a particular drug maybe partially due to the ability to inhibit apoptosis (13). To examine whether CAE induces the apoptosis of A431 cells, the CAE-treated cells were subjected to DAPI staining. The results of the present study revealed that CAE induced apoptosis in a dose-dependent manner. In addition, CAE-treated cells demonstrated a reduction in ROS-induced MMP (Fig. 5). The results of the present study are supported by previous investigations $(14,15)$; CAE may induce apoptosis damage via the accretion of high ROS levels and a reduction in MMP. It 
has been previously reported that numerous anticancer drugs exert cytotoxic effects on cancer cells via the generation of ROS (15). Furthermore, mitochondria have an important role in ROS. Capsaicin imbalances MMP and mediates oxidative stress leading to apoptosis in pancreatic cancer cells (16). The findings of the present study may contribute to the development of skin cancer treatments as this type of cancer has been reported to exhibit high rates of mortality (17). The effects of CAE on the protein expression levels of mTOR, p-mTOR, PI3K, p-PI3K and AKT were determined using western blot analysis. In addition, CAE-treated cells exhibited a dose-dependent inhibition of mTOR and p-mTOR protein expression and a reduction in PI3K/AKT protein expression.

In conclusion, the findings of the present study indicated that CAE may be a potential treatment for skin cancer by targeting the mTOR/PI3K/AKT signaling cascade. As available treatment options are limited, naturally occurring CAE may be considered a potential treatment for skin cancer due to its associated low toxicity; however, further investigation in vivo is required.

\section{References}

1. de Gruijl FR: Skin cancer and solar UV radiation. Eur J Cancer 35: 2003-2009, 1999.

2. Donaldson MR and Coldiron BM: No end in sight: The skin cancer epidemic continues. Semin Cutan Med Surg 30: 3-5, 2011.

3. Aitken JF, Elwood M, Baade PD, Youl P and English D: Clinical whole-body skin examination reduces the incidence of thick melanomas. Int J Cancer 126: 450-458, 2010.

4. Hollman PC and Katan MB: Dietary flavonoids: Intake, health effects and bioavailability. Food Chem Toxicol 37:937-942, 1999.

5. Nagaoka T, Banskota AH, Tezuka Y, Saiki I and Kadota S: Selective antiproliferative activity of caffeic acid phenethyl ester analogues on highly livermetastatic murine colon 26-L5 carcinoma cell line. Bioorg Med Chem 10: 3351-3359, 2002.

6. Takagaki N, Sowa Y, Oki T, NakanishiR, Yogosawa S and Sakai T: Apigenin induces cell cycle arrest and $\mathrm{p} 21 / \mathrm{WAF} 1$ expression in a p53-independent pathway. Inter J Oncol 26: 185-190, 2005.
7. Le Marchand L: Cancer preventive effects of flavonoids-A review. Biomed Pharmacother 56: 296-301, 2002.

8. Alonso DF, Farías EF, Urtreger A, Ladeda V, Vidal CC and Bal De Kier Joffe E: Characterization of F3II, a sarcomatoid mammary carcinoma cell line originated from a clonal subpopulation of a mouse adenocarcinoma. J Surg Oncol 62: 288-297, 1996.

9. Tapia O, Riquelme I, Leal P, Sandoval A, Aedo S, Weber H, Letelier P, Bellolio E, Villaseca M, Garcia P and Roa JC: The $\mathrm{PI} 3 \mathrm{~K} / \mathrm{AKT} / \mathrm{mTOR}$ pathway is activated in gastric cancer with potential prognostic and predictive significance. Virchows Arch 465: 25-33, 2014

10. Azuma M, Tamatani T, Ashida Y, Takashima R, Harada K and Sato M: Cisplatin induces apoptosis in oral squamous carcinoma cells by the mitochondria-mediated but not the NF-kappaB-suppressed pathway. Oral Oncol 39: 282-289, 2003.

11. Cárdenas M, Marder M, Blank VC and Roguin LP: Roguin Antitumor activity of some natural flavonoids and synthetic derivatives on various human and murine cancer cell lines. Bioorg Med Chem 14: 2966-2971, 2004.

12. Yoneda K, Yamamoto T and Osaki T: p53- and p21-independent apoptosis of squamous cell carcinoma cells induced by 5-fluorouracil and radiation. Oral Oncol 34: 529-537, 1998

13. Ferreira CG, Epping M, Kruyt FA and Giaccone G: Apoptosis: Target of cancer therapy. Clin Cancer Res 8: 2024-2034, 2002.

14. Ding H, Han C, Guo D, Chin YW, Ding Y, Kinghorn AD and D'Ambrosio SM: Selective induction of apoptosis of human oral cancer cell lines by avocado extracts via a ROS-mediated mechanism. Nutr Cancer 61: 348-356, 2009.

15. Trachootham D, Alexandre J and Huang P: Targeting cancer cells by ROS-mediated mechanisms: A radical therapeutic approach? Nat Rev Drug Discov 8: 579-591, 2009.

16. Pramanik KC, Boreddy SR and Srivastava SK: Role of mitochondrial electron transport chain complexes in capsaicin mediated oxidative stress leading to apoptosis in pancreatic cancer cells. PLoS One 6: e20151, 2011.

7. Elwood JM, Lee JA, Walter SD, Mo T and Green AE: Relationship of melanoma and other skin cancer mortality to latitude and ultraviolet radiation in the United States and Canada. Int J Epidemiol 3: 325-332, 1974.

This work is licensed under a Creative Commons Attribution-NonCommercial-NoDerivatives 4.0 International (CC BY-NC-ND 4.0) License. 